\title{
Rescate utópico: el tránsito de Sánchez Vázquez desde el marxismo como superación de la utopía al marxismo como vertiente del utopismo
}

\section{Utopian rescue: the transit of Sánchez Vázquez from Marxism as an overcoming of utopia to Marxism as a strand of utopianism}

ARTÍCULO

\author{
Sergio Blanco Gonzalia \\ Contacto: blancogonzaliasergio@yahoo.com
}

Recibido: agosto de 2020

Aceptado: octubre de 2020

\section{Resumen}

El presente artículo aborda la modificación del posicionamiento del filósofo marxista hispano-mexicano Adolfo Sánchez Vázquez ante el concepto "utopía", desde una interpretación peyorativa del mismo (en sintonía con el mainstream marxista) hacia una relectura rehabilitadora ensayada a partir de fines de la década de 1980, lo que implica una reevaluación de los vínculos entre utopía y marxismo. Esta evolución de su pensamiento ante el concepto "utopía" evidencia una revisión más general de su interpretación del marxismo, particularmente respecto a la relación entre sus componentes científicosexplicativos y justificativos-valorativos, donde esta última dimensión adquiere un relevancia creciente en desmedro de la primera. La evolución del pensamiento de Sánchez Vázquez resulta así una clara evidencia del "giro normativo" que sufriera el marxismo en las últimas décadas, manifiesto en distintos pensadores de diversas geografías y trayectorias académicas.

Palabras clave: Utopía; Marxismo; Sánchez Vázquez.

\begin{abstract}
This article addresses the modification of the position of the Spanish-Mexican Marxist philosopher Adolfo Sánchez Vázquez regarding the concept of "utopia", from a pejorative interpretation of it (in tune with the Marxist mainstream) to a rehabilitative rereading rehearsed from the end of the 1980s, which implies a reassessment of the links between utopia and Marxism. This evolution of his thought before the concept of "utopia" evidences a more general revision of his interpretation of Marxism, particularly regarding to the relationship between its scientific-explanatory and justificative-evaluative components, where this last dimension acquires an increasing relevance in detriment of the first. Thus, the
\end{abstract}


evolution of Sánchez Vázquez's thought is a clear evidence of the "normative turn" that Marxism suffered in recent decades, manifested in different thinkers from diverse geographies and political and academic backgrounds.

Keywords: Utopia; Marxism; Sánchez Vázquez.

\section{Introducción}

Aunque de limitada difusión en Argentina, la obra del filósofo marxista Adolfo Sánchez Vázquez (1915, Algeciras - 2011, Ciudad de México) ha tenido una gran circulación y reconocimiento en otros países de habla hispana, principalmente en México. Combatiente republicano en la guerra civil española, miembro del Partido Comunista Español, inició en su exilio mexicano su obra teórica y su trayectoria académica, alcanzando un reconocimiento como "maestro" que "formó y acompañó a sucesivas generaciones de pensadores críticos no sólo de la Facultad de Filosofía y Letras de la UNAM sino de otras facultades y universidades y de otros espacios" (Barreda, 2011). Combinó durante varios lustros su labor teórica y académica con su militancia en el Partido Comunista Español en el exilio, rompiendo con éste a mediados de la década de 1960, aunque manteniendo su compromiso con la causa comunista por fuera de la militancia partidaria. Su pensamiento cobrará entonces una densidad mayor, dando lugar a una interpretación "praxeológica" del marxismo (cuya exposición más acabada se encuentra en su Filosofía de la praxis-Sánchez Vázquez, 1980-) que le permite superar su inicial formación signada por la ortodoxia soviética: el marxismo de Sánchez Vázquez, entonces, se encuentra en la antípodas de la cerrazón dogmática.

Sirvan las líneas anteriores como una antesala necesaria a la hora de encarar el tema del presente artículo: el modo en que este marxista abierto, renovador, afrontó el concepto de "utopía". En función de tal propósito, el primer apartado (1) se propone comentar brevemente las líneas interpretativas establecidas por Marx y Engels respecto a la utopía, dando cuenta con ello de la genealogía del pensamiento de Sánchez Vázquez sobre el tópico. El siguiente paso (2) nos colocará ya en nuestro eje: establecer que en el pensamiento de Sánchez Vázquez respecto a la utopía no se advierte, contrariamente a lo que él mismo sostuvo, continuidad, sino una marcada ruptura acaecida hacia fines de la década de 1980. Para demostrar esto, se procederá en el siguiente movimiento (3) a analizar una obra escrita por nuestro autor en 1970 que resulta fundamental para nuestra indagación: Del socialismo científico al socialismo utópico. Veremos cómo allí se ofrece una secuencia de modelos utópicos (3.1), se decantarán las tesis que Sánchez Vázquez sostuvo en torno a la utopía (3.2), se indicará el modo en que la estrategia interpretativa del marxismo defendida por Sánchez Vázquez subsume la dimensión utópica en el movimiento histórico 
real (3.3), para finalmente establecer que, para Sánchez Vázquez, el resurgimiento de la utopía en el marxismo es señal de una degradación práctica y teórica del mismo (3.4).

En el último de los apartados (4) se analiza un puñado de artículos que corresponden a la producción tardía de Sánchez Vázquez (desde fines de la década de 1980), y se contrasta con lo expuesto en el paso anterior. Así, se abordará el modo en que, en aquellos convulsivos años signados por la disolución de la URSS, nuestro autor modifica sus postulados respecto a la utopía. Un cambio de época que replantea, para Sánchez Vázquez, la relación entre utopía y socialismo (4.1), conduciéndolo a repensar sus postulados acerca del carácter intrínsecamente irrealizable de lo utópico, así como de la relación entre utopía y realidad (4.2), de la relación entre utopía y marxismo (4.3); finalizamos, a modo de balance, con una enumeración de las reconsideraciones de Sánchez Vázquez respecto a la utopía (4.4).

La conclusión se propone, a partir de retomar los desarrollos anteriores, explicar este rescate utópico por parte de Sánchez Vázquez, tanto en lo que respecta al salvataje que el marxismo realiza de la utopía, como al salvataje que la terra utópica puede ofrecerle al marxismo.

\section{Utopía y marxismo}

En diversos escritos de Marx y Engels (1980) se advierten dos movimientos en su reflexión acerca del utopismo. Primero, hay un reconocimiento de una filiación común, que se remonta hacia tiempos lejanos, cuyos antepasados inmediatos son los socialistas utópicos de principios del siglo XIX (y entre ellos, el panteón lo conforman Robert Owen, Charles Fourier y Henri de Saint-Simon). En este sentido, Marx y Engels ofrecen sobradas muestras de gratitud hacia estos socialistas utópicos, valorando las agudas observaciones que realizaron sobre las sociedades en que vivían, así como también algunos de sus pronósticos en torno a ciertas verdades del socialismo. Un famoso pasaje revela la admiración sentida por Engels (1980) hacia estos "gigantes", y nos introduce en el segundo movimiento, de carácter crítico:

[E]l socialismo teórico alemán jamás olvidará que se sostiene sobre los hombros de Saint-Simon, Fourier y Owen - tres pensadores que, a pesar del carácter fantástico y de todo el utopismo de sus doctrinas, pertenecen a las mentes más grandes de todos los tiempos, habiéndose anticipado genialmente a una infinidad de verdades, cuya exactitud estamos demostrando ahora de un modo científico (pp. 179, 180).

De modo que los socialistas utópicos de principios del siglo XIX intuían verdades, las presagiaban (primer movimiento), pero no contaban con un análisis científico de la realidad (segundo movimiento). Sin embargo, según entendían Marx y Engels (2017), estos utopistas estaban justificados en sus fallos, debido a que la inmadurez del capitalismo (escaso 
desarrollo de las fuerzas productivas y del proletariado, y por consiguiente de la lucha de clases), hacía imposible reconocer los elementos de la nueva sociedad en la sociedad existente, por lo que los socialistas utópicos tuvieron que apelar completamente a su imaginación. El insuficiente desarrollo del capitalismo impedía que pueda visualizarse el socialismo como el sucesor natural del capitalismo, recayendo la fundamentación de aquel en las buenas intenciones de los utopistas.

Empero, a los ojos de Marx y Engels (2017) los socialistas utópicos de la segunda mitad del siglo XIX, con un capitalismo ya maduro, no tenían justificación, por lo que su condena no encuentra atenuantes. Así, reprocharán a los socialistas utópicos que su pensamiento se pierda en fantasías acerca de la nueva sociedad, en lugar de apreciar las fuerzas actuantes (económicas, sociales y políticas) que socavan la sociedad existente y perfilan su sustitución. Marx y Engels entienden, y esta es la base de su encono (sin dejar a un lado, tal como advierte Martin Buber -1966-, las motivaciones políticas que tuvieron en su condena a los socialistas utópicos, los cuales eran sus directos competidores), que los utopistas desprecian la necesidad del conocimiento objetivo y la rigurosidad científica, careciendo de realismo para interpretar el desarrollo social y las posibilidades inscritas en él. Estas posibilidades reales del momento histórico sí pueden ser (y son) descubiertas al utilizarse un instrumental analítico adecuado, es decir el proporcionado por la concepción materialista de la historia, y ello permite orientar una autentica transformación revolucionaria. En contraposición, los utopistas, teóricamente impotentes, obstaculizan el camino de la ciencia y conducen a una práctica no revolucionaria, e incluso directamente reaccionaria, distrayendo con construcciones idealistas al proletariado del cumplimiento de su misión histórica.

En síntesis, Marx y Engels no acusaban a los utópicos de ser exageradamente optimistas, sino de carecer de una concepción realista de cómo el socialismo se materializaría. Advierten que en su crítica moralizante al capitalismo los socialistas utópicos señalaron los males de éste, pero no cómo emergería el socialismo como su sustituto. De este modo, la práctica utópica se realizaba desde fuera, como aplicando los ideales socialistas sobre un espacio vacío donde erigirían un nuevo sistema. Tal como señala Gerald Cohen (2001), desde la perspectiva de Marx y Engels esta falta de realismo era consecuencia de que la concepción utópica se justificaba en principios de pretendida validez universal de libertad y justicia, y no basada en las necesidades de la época, de lo posible y necesario históricamente.

Así, este criterio para definir al utopismo, entendido principalmente como una fase precientífica del pensamiento social, sustenta el trazado de una firme línea divisoria entre socialismo utópico y socialismo científico: el primero conducente al engaño y la impotencia, el segundo a la verdad y la guía segura. La concepción materialista de la historia sustituye y supera científicamente a la utopía. 
Esta demarcación será recogida y profundizada por la mayoría de los marxistas posteriores, donde el anti-utopismo es la contracara del énfasis en el carácter científico del marxismo, factor decisivo para orientar la acción política. Asimismo, la distinción entre socialismo utópico y científico afirma la carencia de cientificidad del primero, al tiempo que sugiere la prescindencia (o irrelevancia) de una dimensión moral en el segundo, lo que, en lecturas extremas, deriva en concebir al marxismo como una ciencia sin ideales. De este modo, mientras el utopista apunta a lo que debe ser, el marxismo, desde una supuesta cientificidad centrada en la captación de lo determinado, señalaría lo que será. Veamos a continuación cómo abordó la cuestión de la utopía el renombrado filósofo marxista hispanomexicano Adolfo Sánchez Vázquez, pasando así al tema del presente artículo.

\section{La utopía en Sánchez Vázquez}

Adolfo Sánchez Vázquez, filósofo marxista de profusa y dilatada trayectoria, es el autor de una difundida obra acerca del socialismo utópico y su relación con el marxismo: Del socialismo científico al socialismo utópico. Este excepcional trabajo se basa en las conferencias que dictó en los cursos de invierno de la Facultad de Ciencias Políticas y Sociales de la UNAM, en el año 1970. Treinta y cinco años después de haberlas impartido, rememora el acontecimiento en una serie de conferencias de carácter autobiográfico recogidas en el volumen Una trayectoria intelectual comprometida. Así, en el siglo XXI, Sánchez Vázquez (2006) señala que lo que se proponía en aquella obra de la década del setenta era

esclarecer en qué consistía el verdadero carácter científico del socialismo y de rescatar su contenido utópico visto sólo negativamente por Engels, con lo cual ambos aspectos -el científico y el utópico - lejos de excluirse se conjugaban [...] Se hacía necesario entonces pasar del "socialismo científico" que excluye la utopía a un "socialismo utópico" que, lejos de excluir la ciencia, la necesita para fundamentar la posibilidad de transformar la utopía en realidad (p. 114).

Como veremos a continuación, no es esto lo que Sánchez Vázquez escribió en 1970. Por entonces su valoración de la utopía es marcadamente negativa, siendo central en ello su carácter irrealizable. Asimismo, el texto, no se propone fomentar o fundamentar la necesidad de un tránsito hacia un socialismo utópico, sino justamente lo contrario: evitar la deriva hacia el cenagoso terreno de lo utópico (tránsito que en aquellos tiempos Sánchez Vázquez creía se estaba operando entre las fuerzas socialistas). No hay entonces persistencia en su reflexión acerca de la utopía, sino una ruptura que implica, desde fines de la década de 1980, un reposicionamiento del lugar de lo utópico, expresión, veremos luego, de la re-jerarquización de la dimensión justificativa-valorativa en su pensamiento. 


\section{La utopía según Sánchez Vázquez en 1970}

¿Cuál era la visión acerca de lo utópico que sostenía Sánchez Vázquez previo al giro que efectuara hacia fines de la década de 1980? Para responder tal interrogante su Del socialismo científico al socialismo utópico resulta clave. El título de este trabajo resulta insinuante, ya que invierte los términos del título con que fuera conocido en lengua castellana el famoso opúsculo de Engels (1998): Del socialismo utópico al socialismo científico. Guiándonos por esta inversión, pareciera que Sánchez Vázquez sugiere desandar el camino recorrido por el marxismo, y abrevar en las fuentes tan vilipendiadas de la utopía. Pero como anticipamos, lejos de esto el autor se propone lo contrario: subrayar la demarcación entre el socialismo marxista y la utopía.

El concepto de utopía en Del socialismo científico al socialismo utópico tiene una profunda carga negativa. Aunque Sánchez Vázquez rescata el elemento ideal-valorativo que, entiende, debe ser parte de todo proyecto emancipador, la tesis que sostiene en este escrito de 1970 es que la teoría socialista está perdiendo cientificidad y recostándose cada vez más en postulados utópicos, lo cual no es considerado positivamente por el autor. El utopismo aparece así como una amenaza, un modo de pensar que se supuso superado, pero que estaría reemergiendo e inficionando el cuerpo teórico del marxismo: "La utopía no puede volver a colarse por la misma puerta por la que fue arrojada; pero ¿no habrá entrado por otra?" (Sánchez Vázquez, 2000, p. 22).

\subsection{Tres "modelos" de utopía}

Sánchez Vázquez parte de distinguir tres "modelos" de utopía, siguiendo en esto (aunque sin explicitarlo) la secuencia propuesta por Karl Mannheim (1971). En primer lugar, distingue la utopía platónica, donde el tránsito de lo real a lo ideal es asumido como infranqueable, lo que conllevaría una utopía "vertical", que postula un "cielo" inaccesible, y que debido a su carácter perfecto no puede realizarse ni hoy ni nunca, está fuera de todo tiempo. Al desterrar cualquier esperanza de realización, no quiere ni puede impulsar una praxis política. No hay en ella una dimensión humana de lo posible y realizable. Este modelo de utopía lo advierte también en la utopía cristiana medieval del "reino de Dios". Será recién con la utopía anabaptista de Thomas Müntzer donde el reino celestial se conjuga con el reino terreno, producto de la actividad humana (y aquí Sánchez Vázquez sigue, sin dar cuenta de ello, a pensadores marxistas como Karl Kautsky -1897- y Ernst Bloch -1921-). De este modo, la gesta del predicador revolucionario alemán es visualizada por Sánchez Vázquez como una transición hacia el segundo modelo: la utopía renacentista moderna. Esta fase transitoria asienta la idea subyacente en la periodización formulada por nuestro 
autor: el movimiento desde lo utópico entendido como irrealizable por los hombres, a lo utópico concebido como algo que podría ser realizable, aunque de hecho no lo es.

De manera que en este segundo modelo, la utopía renacentista, el tránsito entre lo ideal y lo real ya no es visualizado como infranqueable. Se describen los males de la sociedad existente, se señalan también sus causas (la propiedad privada, el afán de poder, etc.), y la crítica de lo existente es acompañada por la postulación de modelos alternativos. Aquí la utopía tiene un lugar, sea la Nueva Atlántida, la Ciudad del Sol en la isla Taprobana, u otro, lo cual puede alentar la esperanza. Sin embargo, Sánchez Vázquez (2000) interpreta que lo que no tiene lugar es la voluntad de realización, o al menos no se advierte un esfuerzo práctico transformador: "[E]n los grandes utopistas del Renacimiento los grandes proyectos de estructuración social no van acompañados de una voluntad real de transformación" ( $p$. 23). Es esto lo que mantiene a la utopía renacentista en el terreno de lo imposible, asemejándola a la utopía platónica.

En tercer lugar se encuentran las utopías propuestas por los socialistas utópicos del siglo XIX. Sánchez Vázquez entiende que los diferencia de los anteriores utopistas, primero, el posicionarse y defender el punto de vista de un sector determinado de la sociedad (y no dirigirse indistintamente a todas las clases y sectores): el proletariado. $\mathrm{Y}$ segundo, el advertirse en ellos una voluntad de transformación real, un ánimo práctico transformador: las sociedades proyectadas deben hacerse realidad, son concebidas como posibles y se impulsa su plasmación. De hecho algunos experimentos son llevados a cabo, aunque estos "islotes" utópicos, a modo de anticipo de la sociedad futura, fracasan estrepitosamente. El querer e intentar no resulta suficiente para realizar. El ideal propuesto tanto como los medios para alcanzarlo son, considera Sánchez Vázquez, irrealizables. Ésta es la denotación fundamental de lo utópico para nuestro autor en aquella época.

Sánchez Vázquez propone, asimismo, una distinción al interior de los socialistas utópicos entre aquellos que apelan a medios reformistas y los que proponen vías revolucionarias. Entre los primeros se cuentan Charles Fourier y Étienne Cabet, quienes apostaban a la fuerza del ejemplo y la persuasión, y Robert Owen, que enfatizaba el rol de la educación en la transformación moral: todos ellos niegan cualquier papel a la violencia en la consecución de los fines propuestos (y ello, para Sánchez Vázquez, devela su condición de irrealizables). Por otro lado, el utopismo revolucionario, a diferencia del reformista, no se concentra en las características que habrá de tener la sociedad futura, se despreocupa por aquello que hay en la "otra orilla" y pone toda la tensión en cruzar el río. Al concebir el paso hacia la utopía como producto esencialmente de la voluntad, desmerecen las condiciones objetivas, las posibilidades existentes para el cambio, y lo apuestan todo a la acción organizada de una minoría, o al emerger espontáneo de la masa. Esto, nos dice Sánchez Vázquez, conduce también a la irrealizabilidad, y por ello son utópicos: el deseo y la voluntad 
de realización que manifiestan estos utopistas, ausentes en las utopías anteriores, son, sin embargo, insuficientes.

\subsection{Once tesis sobre el utopismo socialista}

¿Cuáles son, entonces, las características del utopismo socialista? Siguiendo el trabajo de Sánchez Vázquez del año 1970, se formulan once tesis.

Primera: el utopismo socialista es una representación imaginaria sobre la sociedad futura, propone algo inexistente, imaginado, pero que no está fuera del tiempo y el espacio (como en las anteriores utopías), sino que se inserta en el fluir del tiempo, se encuentra en el porvenir. En síntesis, podría decirse que para nuestro autor la utopía pasó a ser ucronía, en tanto buen tiempo futuro, anticipatoria del "buenvenir".

Segunda: se anhela realizar la sociedad deseada. El futuro entrevisto es valorado positivamente, ya que es mejor a lo existente, lo que impulsa a la realización, a la plasmación.

Tercera: "La utopía es una idea no realizada; realizable a los ojos del utopista, pero, en definitiva, irrealizable" (Sánchez Vázquez, 2000, p. 27). Desde la óptica del utopista no es irrealizable, pero de hecho sí lo es, ya sea por la desmesura del fin, por la imposibilidad de plasmarlo partiendo de las condiciones objetivas existentes, o por lo inadecuado de los medios. El sino de la utopía es la impotencia.

Cuarta: la proyección imaginaria de la sociedad futura arraiga en el presente. Nuestro autor indica que los socialistas utópicos del siglo XIX estaban impedidos de superar la dimensión utópica dada la inmadurez de las condiciones objetivas existentes. El utopismo tenía que compensar con imaginación lo que el análisis científico no podía cubrir.

Quinta (continuación de la anterior): el utopismo es un producto histórico necesario, dada la inmadurez de las condiciones existentes para desarrollar una teoría y una práctica revolucionaria científicas.

Sexta: la utopía tiene una relación ilusoria con el presente; concibe lo real existente como negativo, pero no lo conoce verdaderamente (porque no es ciencia) sino que lo imagina. Su crítica a la realidad puede contener elementos de verdad, pero no más.

Séptima: La utopía tiene una existencia real (como ideología), se encuentra en el mundo real en tanto idea que se aspira a realizar. Genera prácticas (comunas, falansterios, acciones violentas), y por ello es una forma de praxis, aunque inauténtica, estéril.

Octava: la utopía entraña la destrucción de la unidad de teoría y práctica. Lo que la utopía pretende realizar no surge de la práctica, sino que es producto de la imaginación. La teoría prima sobre la práctica, se impone a ella, y rompe la unidad de teoría y praxis. Tampoco se corrige mediante la práctica, sino que mantiene sus esquemas imperturbablemente. 
Novena: mientras la ciencia anticipa en base al conocimiento de las condiciones realmente existentes, la utopía anticipa en base a la imaginación. Cuando la ciencia no puede anticipar, entonces la utopía cubre su lugar, y cuando la ciencia sí puede anticipar, entonces la utopía retrocede. La utopía brilla o se apaga de acuerdo a la menor o mayor posibilidad de anticipación de la ciencia.

Décima: el utopismo no es consciente de su condición, y por ello considera que su proyecto es realizable. Para superar el utopismo hay que ser consciente de ello.

Undécima: "Los utopistas se han limitado a imaginar el mundo futuro de distintos modos; de lo que se trata es de construirlo" (Sánchez Vázquez, 2000, p. 31). Aquí Sánchez Vázquez parece negar lo dicho anteriormente, ya que resulta claro que los socialistas utópicos no se limitaron a imaginar el mundo, sino que buscaron transformarlo ya sea por la vía de la reforma o de la revolución. Pero podemos interpretar que de lo que se trata es de construirlo exitosamente, con lo cual volvemos a la sentencia de la irrealizabilidad como nota característica del utopismo.

De modo que el socialismo utópico, según Sánchez Vázquez, propone una ucronía (1), impulsando activamente a su realización (2), ya que cree que es posible, aunque ciertamente es imposible (3). El socialismo utópico surge necesariamente producto de la inmadurez de las condiciones objetivas (4) que impedían desarrollar una práctica y una teoría revolucionarias científicas (5), lo cual significa una teoría no-científica incapaz de aprehender la realidad (6), y una práctica real aunque impotente (7). El socialismo utópico desintegra la unidad de teoría y práctica, ya que se trata de una teoría que no surge de la práctica real ni se ve influenciada por ésta (8); sus anticipaciones son producto de la imaginación, no de la ciencia, y su auge se explica por las carencias del pensamiento científico (9). El utopismo es inconsciente de su carácter utópico, es decir, de su irrealizabilidad (10); es preciso superarlo ya que de lo que se trata es de transformar realmente (exitosamente) el mundo (11).

\subsection{La superación científica del socialismo utópico: la fusión del ser y el deber ser}

En la década de 1970 Sánchez Vázquez entiende que los utopistas desarrollan una praxis degradada, inauténtica, ya que se encuentran al margen de la praxis real. Esto, afirma, se interrelaciona con su carencia de instrumental analítico adecuado (científico), que los conduce a una interpretación ilusoria del mundo. De este modo, no contribuyen a la transformación radical de la realidad, desviando la praxis revolucionaria. Por eso, nos dice, resultaba imprescindible para Marx una crítica del utopismo, ya que era una necesidad práctica revolucionaria:

[P]ara pasar a una transformación efectiva del mundo social, era preciso operar también una transformación radical en el plano del pensamiento: pasar de la utopía a 
la ciencia; o sea, de una interpretación imaginaria de lo real a otra, objetiva y fundada.

(Sánchez Vázquez, 2000, p. 32)

El punto de partida de Marx, indica Sánchez Vázquez, es la distinción entre el utopismo del tiempo anterior al capitalismo maduro que, pese a sus limitaciones históricas insuperables, resultaba positivo por su crítica a la sociedad existente, y el utopismo posterior que resulta regresivo en toda la línea, debido a que ya se encuentran dadas las condiciones para un análisis científico del devenir de la sociedad capitalista. El eje central de las implicancias del cambio de época reside, para Sánchez Vázquez, en que el socialismo propuesto por Marx no se articula en torno a ideas inventadas, sino que es el resultado al que arriba el movimiento histórico, descubierto tras el estudio objetivo de las condiciones reales: "[S]ocialismo científico quiere decir teoría científica de la sociedad y de la historia, teoría que permite hacer ciertas predicciones inferidas -a diferencia de las anticipaciones imaginativas de las utopías- del conocimiento de las condiciones reales existentes" (Sánchez Vázquez, 2000, p. 34). Desde entonces, indica nuestro autor, la praxis revolucionaria se fundará no en el mero deseo, sino en el conocimiento científico de lo real.

Sánchez Vázquez señala que el socialismo en Marx aparece como producto de una necesidad histórica objetiva, y por tanto como algo que es (será), y al mismo tiempo, esta nueva sociedad aparece como deseable, como algo que debe ser. Indica asimismo que al concebir al socialismo como una fase históricamente necesaria, el ser no se deduce del deber ser, y por ello no cae en el redil del utopismo. Pero entonces, se pregunta, ¿el deber ser se deduce del ser? Pensarlo así, nos dice, resulta equivocado, ya que implicaría tener por bueno algo que es necesario históricamente.

¿Excluye el socialismo fundado científicamente todo juicio de valor? Sánchez Vázquez sostiene que Marx demostró la necesidad histórica del socialismo; producto de las contradicciones del capitalismo se desarrollan las condiciones materiales para su aparición. Pero para que efectivamente "aparezca" el socialismo es necesaria la labor teórica y práctica de los explotados. Por tanto, aparece como requisito la toma de conciencia por parte de los agentes revolucionarios de la necesidad del socialismo, y de la necesidad de luchar por él ya que constituye algo valioso, un ideal, pero un ideal no utópico, sino fundado, realizable, que requiere de premisas materiales y también políticas e ideológicas. El socialismo, entonces, es (será) y debe ser:

La comprensión de su superioridad o valor es un factor decisivo en la lucha revolucionaria por el socialismo [...] tienen que estar convencidos que luchan por algo valioso y, además, por algo que tiene un valor superior al mundo social en que viven. (Sánchez Vázquez, 2000, p. 38)

Esta es la estrategia interpretativa que Sánchez Vázquez despliega en su lectura del marxismo, donde el discurso justificativo se integra en el discurso explicativo. De esta 
manera, para él no puede haber un socialismo necesario y otro deseado. No hay dos, sino un socialismo: "El socialismo necesario es, a la vez, el deseado. $Y$ el socialismo deseado tiene que ser el socialismo necesario, es decir, el que se halla inscrito como posible [...] en un movimiento histórico real" (Sánchez Vázquez, 2000, p. 39). El socialismo no es valioso por ser necesario (hay necesidades históricas no deseadas), ni es necesario por ser valioso (eso significaría caer en el utopismo). Considerar, como se hace desde una interpretación cientificista del marxismo, al socialismo como necesario históricamente pero ajeno a su deseabilidad, impide comprender la lucha de los hombres por su realización. Y concebirlo como un ideal deseado independiente de las condiciones necesarias para su realización significa caer en un enfoque utopista.

\subsection{El retroceso del marxismo hacia el socialismo utópico y la necesidad de restablecer su} carácter científico

Como fue señalado anteriormente, el título $\mathrm{Del}$ socialismo científico al socialismo utópico no tiene una función prescriptiva sino interpretativa: por aquellos años de la década de 1970, Sánchez Vázquez considera que el utopismo gana terreno en la teoría y la práctica socialista, y ello no le parece una buena noticia.

El primer eje de su crítica es el partido leninista. Sin duda, afirma, resultó fundamental para la conquista del poder por parte del proletariado ruso. Empero, advierte que, lo que en Rusia resultó fundamental, al trasladarse mecánicamente a otras latitudes significó caer en el utopismo de considerar que todo depende de la organización leninista de partido. Este "utopismo organizativo", que habría encarnado en intelectuales como Georg Lukács e incluso en futuras víctimas de la omnipotencia del partido como León Trotsky, condujo a identificar en cualquier circunstancia al partido con la verdad y con la revolución. Sin embargo, nuestro autor fue testigo de cómo los partidos leninistas podían burocratizarse, aislarse de las masas, cometer injusticias y todo tipo de aberraciones. La raíz de este utopismo, indica, se encuentra en la falsa teoría de la conciencia socialista como algo inyectado desde el exterior al movimiento obrero, concepción que implica que el partido es siempre el educador, y por tanto desconoce la Tesis III de las Tesis sobre Feuerbach de Marx (1980), que afirma que el educador necesita a su vez ser educado.

En segundo lugar, Sánchez Vázquez observa elementos utópicos en la construcción del socialismo, en torno a la creencia en la positividad plena de la revolución. Así, la revolución socialista acaecida sería pura, impoluta, y también la última, la definitiva, el acto final de la historia absolutamente irreversible. De esta manera, la utopía propagada desde la "ortodoxia" oficial soviética habría servido para ocultar la verdadera situación de los países que abolieron la propiedad privada de los medios de producción, y los desafíos que entonces enfrentaban en la construcción del socialismo. Y la utopía organizativa anteriormente 
mencionada resultaba funcional al mantenimiento de este estado de cosas, en tanto impedía cualquier valoración crítica del accionar del partido.

Finalmente, Sánchez Vázquez señala que aquello que Marx entendía como utópicoirrealizable apareció como realidad. Por un lado, revoluciones en países atrasados sin centralidad de la clase obrera e incluso sin dirección política por parte de un partido revolucionario; es decir, sin emergencia de los sujetos sociales y políticos "clásicos". Por otro lado, lo que parecía un devenir cercano, la revolución en los países industrializados de Europa, se fue haciendo cada vez más improbable. Así, mientras el marxismo en el bloque socialista se refugiaba en la utopía, era incapaz de explicar lo que sucedía en el Primer y Tercer Mundo. Así, la utopía emerge cuando falta "un verdadero conocimiento de lo real, es decir, cuando la ciencia social se queda a la zaga de los movimientos reales, y los conceptos tradicionales, usados dogmáticamente, no pueden ya dar razón de esos cambios" (Sánchez Vázquez, 2000, p. 59).

En aquellos comienzos de la década 1970 Sánchez Vázquez cree estar vivenciando un renacimiento de la utopía (lo cual, para él, no constituye una buena cosa), que es producto de las dificultades teóricas y prácticas acumuladas en la lucha por el socialismo y los cambios operados en el capitalismo. La utopía surge cuando la ciencia no puede explicar lo real, y la tarea de los marxistas, advierte, es restablecer el carácter científico del marxismo (punto en el coincide, más allá de otras divergencias, con Louis Althusser):

La empresa de Marx y Engels de poner el socialismo sobre una base científica y no utópica sigue siendo legítima en cuanto que el utopismo refleja una pérdida de contacto con lo real y, como consecuencia, una crisis de la organización y de la lucha al faltar ese suelo nutricio (Sánchez Vázquez, 2000, p. 64).

\section{Sánchez Vázquez y el marxismo como utopía: 1989 y después}

Hacia mediados de la década de 1980, Sánchez Vázquez ensayará una suerte de balance y revisión (a veces explícita, a veces no) de los postulados que otrora sostuviera. Ello comprende su reposicionamiento en torno a la utopía (aunque todavía pueden encontrarse en sus escritos de esta última etapa aisladas "recaídas" en un uso peyorativo del término), tema del presente artículo.

En dos trabajos escritos en el convulso trienio de 1989-91, Sánchez Vázquez reelabora su concepción de la utopía y su vínculo con el marxismo. A continuación procederemos a su análisis, agregando luego un tercer trabajo escrito a mediados de la década del noventa, donde el autor termina de delinear su nueva comprensión de la relación entre el marxismo y lo utópico, inscribiendo a aquel como una variante de este pensamiento.

\subsection{El socialismo como utopía de futuro}


El primer trabajo lleva por título "En la utopía socialista: ¿de qué socialismo hablamos?", y fue presentado como ponencia en el Encuentro Internacional "El socialismo del futuro", auspiciado por la Fundación Sistema (organización vinculada al Partido Socialista Obrero Español), que tuvo lugar en Madrid en los últimos días de septiembre de 1989. Allí, Sánchez Vázquez parte de afirmar que el socialismo desapareció del horizonte de las masas. Dado que la sustitución del capitalismo por el socialismo no se encontraba a la orden del día en ninguna parte del mundo, nuestro autor afirmaba que el socialismo se convierte en cosa solamente del futuro, sin arraigo en el presente; es decir, en utopía.

Este no-presente del socialismo se complementa con la carencia de referentes en el pasado: el socialismo como proyecto es incompatible con el capitalismo, y por tanto distinto de las experiencias socialdemócratas, así como también es distinto del "socialismo real":

el socialismo nunca ha existido ni existe todavía, realmente. Que, por tanto no es cosa del pasado ni del presente, pero que, dada su necesidad como alternativa al capitalismo, no podemos renunciar a él como utopía para un futuro más o menos lejano. Ahora bien, este socialismo del futuro sólo llegará a ser realidad si, desde ahora y a través de la densa niebla de tergiversaciones y confusiones, permanece como una meta o utopía hacia la cual hay que caminar (Sánchez Vázquez, 2007, p. 290).

La desaparición del socialismo como posibilidad inmediata hace que se transmute en utopía. Pero se advierte que el uso que Sánchez Vázquez hace del término "utopía" no connota irrealizabilidad absoluta, sino momentánea. $\mathrm{Y}$, asimismo, su rescate como proyecto (claramente diferenciado de las políticas de componendas con el capitalismo o las aberraciones del stalinismo) resulta una tarea clave: la persistencia del socialismo como ideal, como utopía, pasa a ser fundamental para la realización futura del socialismo.

\subsection{La utopía como no-irrealizable}

Un año después, Sánchez Vázquez presenta la ponencia "La utopía de Don Quijote" en el IV Coloquio Cervantino Internacional celebrado Guanajuato, México. En primer lugar, parte de declarar que su intención de leer la novela cervantina como utopía es un esfuerzo reivindicatorio de la misma en un tiempo,

un presente, el nuestro, en el que el pragmatismo, el eficientismo y el consumismo impuestos por la lógica de la acumulación capitalista, y el fracaso histórico de los grandes proyectos de transformación social, ponen en cuestión la necesidad y vitalidad de las utopías (Sánchez Vázquez, 2015a, p. 533).

En segundo lugar, nuestro autor enfatiza el carácter subversivo de la utopía, en tanto ésta no acepta lo que es, se propone trascender lo existente. Es siempre una ventana hacia el futuro, siempre está en disonancia con lo existente en el presente. Pero, y he aquí la cuestión, este dispositivo disruptor ya no se caracteriza por su absoluta imposibilidad de 
realización: "[E]sta impotencia -absoluta en ciertas utopías- es relativa y condicionada en otras. El fracaso de hoy puede ser el éxito de mañana. El sueño y la ilusión presentes pueden ser una realidad en el futuro" (Sánchez Vázquez, 2015a, p. 535). En escritos anteriores, el filósofo hispano-mexicano insistía en que el pensamiento utópico era irrealizable no solo en el sentido de que toda plasmación de una idea no se reproduce tal cual lo ideado (es decir, que el proyecto y la realidad están siempre disociados, por ello no puede haber identificación absoluta entre estos planos, etc.: imposibilidad a posteriori), sino también en cuanto a que era inviable su realización aunque sea "imperfecta" (imposibilidad a priori). Esto ahora desaparece: lo "irrealizable" se interpreta solamente como desajuste entre idea y plasmación de la idea, y no en el sentido de que lo utópico es irrealizable intrínsecamente. Por ello, ahora nos propone una distinción entre utopías impotentes para realizarse absolutamente, y otras impotentes solo relativamente, ya que mañana se pueden realizar.

En tercer lugar, dado que en el lenguaje coloquial se asocia "quijotismo" con imposibilidad, Sánchez Vázquez se pregunta por qué fracasa don Quijote en la consecución de su utopía. Y afirma que su fracaso no es consustancial al carácter utópico de su empresa, sino que responde a otras causas, y esas causas residen en las condiciones en que actúa don Quijote, en los límites que imponen las circunstancias, en el tiempo y la sociedad en que vive. $Y$ estas causas están vinculadas a los medios y la evaluación incorrecta de la situación, mas no en una imposibilidad connatural a la utopía: "Las utopías no están forzadas a fracasar inevitablemente” (Sánchez Vázquez, 2015a, p. 543).

Finalmente, Sánchez Vázquez advierte que aquello "que debe ser no puede quedar absorbido por lo que es. La topía no puede imponer su dominio hasta el punto de tragarse la utopía" (Sánchez Vázquez, 2015a, p. 543). Aquí se advierten dos cuestiones. Primero, la asunción por parte del autor del carácter profundamente antiutópico de la "topía" desde la cual él reflexiona. Su alerta apunta a no abandonar los proyectos de superación de lo dado ante el triunfalismo capitalista reinante. En segundo lugar, se reclama para la utopía un espacio propio autónomo de la topía, revelando una escisión entre topía y utopía, entre ser y deber ser, donde una dimensión parece ya no conectar con la otra. Parece que nada de socialismo se encuentra inscrito en la topía. Si en sus escritos de años anteriores el ser se vinculaba con el deber ser a partir de lo que será (aunque no inevitablemente, sí históricamente necesario), es decir, si la realidad incluía su devenir, y ese devenir incluía el deber ser, ahora lo deseado parece sustentarse únicamente en una apelación moral de repudio al capitalismo y reivindicación de una alternativa socialista.

\subsection{El marxismo como "cuarto momento" de la utopía}

El último trabajo del cual pasaremos revista se titula "La utopía del "fin de la utopía"”, texto que recoge la conferencia pronunciada por Sánchez Vázquez en el "Seminario sobre 
la Utopía", organizado en el marco de los cursos de verano por la Universidad Complutense de Madrid, en agosto de 1995. Allí, retomando la secuencia histórica (descrita más arriba) en torno a las utopías (platónica, renacentista, socialista utópica), nuestro autor agrega ahora un cuarto "momento": el socialista-comunista, que remite a Marx y Engels. Así, el fracaso de los proyectos utópicos anteriores a ellos "no conduce al fin de la utopía, sino a forjar sobre nuevas bases otra nueva. Y ésta es justamente la utopía socialista-comunista de Marx y Engels" (Sánchez Vázquez, 2015b, p. 550).

Sánchez Vázquez toma en consideración que los revolucionarios alemanes no reconocían explícitamente un contenido utópico a su teoría, y más aun, se oponían radicalmente al utopismo. Su obra teórica, indica, se postula como un socialismo científico, opuesto al socialismo utópico (y de ello da cuenta el titulo del famoso opúsculo de Engels). Esta exclusión de lo utópico, indica, fue subrayada por las versiones cientificistas del marxismo, quienes negarán cualquier valor positivo a la utopía. Pero para Sánchez Vázquez (2015b), el utopismo

no sólo forma parte del pensamiento de Marx [...] sino que constituye un aspecto o componente esencial de él, aunque en unidad indisoluble con otros que también lo son, a saber: la crítica de lo existente, el conocimiento de la realidad que se critica y pretende transformar, y su vocación práctica o vinculación con la acción (p. 551).

Nuestro autor reitera su definición clásica del marxismo como conjunción de crítica de lo existente, conocimiento científico, filosofía de la praxis, y proyecto de emancipación, solo que ahora asume, sin ambages, el carácter utópico del marxismo, subrayando que este utopismo no es "superable", sino que es una forma de pensamiento preexistente al marxismo, y en la cual éste se inscribe como un momento más de él. Se advierte claramente un cambio de enfoque, una nueva estrategia discursiva propuesta por Sánchez Vázquez que da cuenta de una nueva situación política y cultural, y del creciente peso en su producción teórica de la dimensión justificativa del marxismo.

\subsection{Nuevas tesis sobre la utopía}

En "La utopía del "fin de la utopía"' Sánchez Vázquez propone un puñado de tesis acerca de la utopía. Su reformulación de lo utópico es claramente advertible al analizarlas y compararlas con las que propusiera en la década de 1970. Así, en este texto de 1995, las nuevas tesis indican:

1) La utopía existe en el mundo ideal, en tanto proyecto emancipatorio. Y se encuentra en el tiempo futuro, ya que se deposita la esperanza en el porvenir.

2) La utopía implica una crítica a lo existente, juzgando éste desde principios y valores que articulan la imagen de una sociedad mejor. 
3) La utopía es irreductible a la realidad, ya que eso significaría el fin de la utopía. Se aproxima a la realidad pero nunca se realiza plenamente, ya que cambia la realidad y con ello cambian las utopías, sucediéndose unas a otras. La utopía, como la realidad, no es estática. Sostener que la utopía no termina de realizarse no es lo mismo que decir que es irrealizable (irrealizabilidad a posteriori, y no irrealizabilidad a priori).

4) Al aspirar a realizarse, la utopía influye sobre la realidad, inspira prácticas encaminadas a lograr la plasmación de la utopía.

5) Las utopías responden a intereses de clases o grupos inconformes frente al actual estado de cosas.

6) En este sentido, la utopía entraña una ideología, ya que es una visión de la realidad de acuerdo a intereses de clase o grupo social.

7) "La utopía se mueve siempre entre dos extremos: lo imposible y lo posible" (Sánchez Vázquez, 2015b, p. 556); "la utopía no es el reino de lo absolutamente imposible, ni tampoco de lo posible sin más, sino de lo posible en determinadas circunstancias y condiciones" (Sánchez Vázquez, 2015b, p. 557). Para que se realice, entonces, requiere de ciertas condiciones objetivas, pero también de la conciencia de su valor, de su superioridad sobre lo existente, de la voluntad de realización y de la praxis correspondiente.

En estas nuevas tesis acerca de la utopía no hay ninguna connotación negativa del término. Comparándolas con las once tesis formuladas en 1970 (véase más arriba) se advierte el cambio de perspectiva. Se equiparan en cuanto ambas formulaciones reconocen en la utopía un proyecto emancipatorio orientado hacia el futuro, y que moviliza prácticas, pero existen diferencias sensibles. Empezando porque en las tesis de 1970 la utopía se define por su imposibilidad de realización, mientras que en el escrito posterior es vista como realizable. En segundo lugar, la crítica de lo existente, revindicada en 1995, es cuestionada en el texto temprano por su carácter no científico, lo que revela una teoría que es producto de la inmadurez de las condiciones existentes, que inspira una práctica asimismo no científica, que se encuentra por fuera de la realidad siendo incapaz de verse influenciada por ésta, lo que resulta en la desintegración de teoría y práctica. En síntesis, la utopía es concebida en las tesis de 1970 como producto de la carencia de un pensamiento científico, y se proclama la necesidad de su superación. Esta relación necesariamente negativa con la ciencia se encuentra ausente en 1995, y la utopía aparece no como un momento que debe ser superado, sino como una constante y el marxismo como uno de sus momentos (y no como su superación).

Para Sánchez Vázquez el marxismo es entonces utopía. Empero nuestro autor no dejará nunca de interpretar que el marxismo es también ciencia, donde el aporte 
específicamente marxiano consiste en "resaltar el momento cognoscitivo, como elemento indispensable de la praxis, para llegar a la nueva sociedad" (Sánchez Vázquez, 2015b, p. 558). Pero estas dos dimensiones aparecen ahora cada una por su lado, la dimensión utópica no se encuentra integrada al discurso científico, sino que lo precede, y así la ciencia (marxista) viene a realizar su aportación a un postulado utópico que la trasciende. La utopía no brota de la inmadurez de las condiciones existentes ni de las carencias del pensamiento científico, sino que es una dimensión perenne, que se manifiesta con mayor o menor intensidad. Asimismo, la utopía ya no aparece como un impedimento para aprehender la realidad, ni para desarrollar una práctica y una teoría revolucionaria, ni tampoco son condenadas sus anticipaciones no-científicas; la "imaginación" utópica se encuentra rehabilitada.

\section{Conclusión}

Hemos iniciado este artículo bosquejando brevemente el posicionamiento de Marx y Engels ante el utopismo: por un lado, reconocen en los socialistas utópicos el hallazgo de ciertas verdades que podemos llamar "morales", de crítica hacia lo existente y postulación de un proyecto social superador. Empero, por otro lado, Marx y Engels cuestionan los planteos de los utopistas en cuanto a su carencia de medios válidos para alcanzar el fin propuesto; de ahí sus críticas a la ausencia de realismo de los socialistas utópicos, y la postulación de su superación a partir de una concepción materialista de la historia que posibilita descubrir las vías para la transición hacia el socialismo.

Esta lectura que concibe al pensamiento utópico como algo definitivamente superado formó parte del acervo de la mayor parte de los marxistas (con contadas excepciones, entre las cuales se destaca la obra de Ernst Bloch), entre ellos Sánchez Vázquez. De acuerdo a su estrategia interpretativa del marxismo, los postulados valorativos-justificativos, es decir, aquellas "verdades morales" que los socialistas utópicos habrían anticipado, quedan subsumidas en un discurso explicativo que devela el movimiento de lo real, el cual permite, y esto es lo esencial, descubrir los medios reales (vale decir, efectivos) para alcanzar el fin anhelado (que no solamente es un fin anhelado, sino también un fin que brota de la misma historia).

Sin embargo, como vimos, hacia fines de la década de 1980 Sánchez Vázquez irá modificando sensiblemente su postura respecto a la utopía: en el marco del "fracaso histórico de los grandes proyectos de transformación social" (Sánchez Vázquez, 2015a, p. 533), el socialismo aparece a sus ojos como irrealizable para los tiempos actuales, como cosa completamente de futuro, sin lazos con la realidad existente; por ello pasará a concebirlo como utopía. Pero si anteriormente Sánchez Vázquez entendía la utopía como irrealizable per se, ahora dirá que la utopía, como el socialismo, es algo irrealizable hoy pero 
realizable en el futuro. En sintonía con esto, Sánchez Vázquez modifica sensiblemente su interpretación de la relación entre utopía y marxismo: el utopismo no es conceptuado como un modo de pensamiento superado por el marxismo, sino que el marxismo es un momento más del pensar utópico. Rescate de la utopía desde el marxismo, eliminación de los deslindes otrora subrayados: la utopía queda rehabilitada en el vocabulario marxista de Sánchez Vázquez (algo que también se puede advertir en otros pensadores marxistas en las últimos décadas).

Pero si el marxismo de Sánchez Vázquez ofrece este rescate de lo utópico, lo hace porque la utopía viene a su rescate: es decir, la terra utópica resulta un ámbito propicio para restañar las heridas, ya que, de fondo, lo que ha entrado en crisis es la estrategia interpretativa del marxismo sostenida por él, la cual subsumía la dimensión justificativavalorativa en la dimensión científico-explicativa. Al tornarse evidente para Sánchez Vázquez la debilidad del marxismo para explicar el movimiento de lo real, y por tanto develar las vías para alcanzar el fin propuesto, la dimensión justificativa-valorativa se independiza del discurso explicativo-científico, y pasa a ser el terreno privilegiado en el cual afinca su marxismo. De ahí que en su producción tardía se aprecie un vuelco cada vez más acusado hacia la filosofía moral, algo que él mismo reconoce (Sánchez Vázquez, 1995).

Esta búsqueda del Sánchez Vázquez tardío de asentar el discurso marxista sobre fundamentos justificativo-valorativos, puede encuadrarse en una tendencia más general del marxismo en las últimas décadas. Tal como indica Cohen (2017), al tornarse evidente que las explicaciones sobre lo fáctico proporcionadas por el marxismo resultaban endebles, el marxismo pasará a presentarse cada vez más como un conjunto de valores y proyecciones modélicas (giro normativo en el cual el marxismo analítico ha sido pionero), lo que resulta en una mayor proximidad al socialismo utópico. Así, la terra utópica, otrora desdeñada por el marxismo, acude a su rescate proporcionándole un hábitat donde persistir como discurso valorativo, mientras busca nuevas herramientas teóricas que le posibiliten vislumbrar vías de realización.

\section{Referencias bibliográficas}

Barreda, A. (14 de julio de 2011). El maestro Adolfo Sánchez Vázquez. La Jornada. Recuperado (08/08/2020): https://www.jornada.com.mx/2011/07/14/cultura/a05a1cul

Bloch, E. (1921). Thomas Münzer, Teólogo de la revolución. Madrid: Ciencia Nueva.

Buber, M. (1966). Caminos de Utopía. México: Fondo de Cultura Económica.

Cohen, G. A. (2001). Si eres igualitarista ¿cómo es que eres tan rico? Barcelona: Paidós. 
Cohen, G. A. (2017). Propiedad de sí, libertad e igualdad. Buenos Aires: Prometeo.

Engels, F. (1980). Adición al Prefacio a la edición de 1870 [de La guerra campesina en Alemania] para la tercera edición de 1875. En K. Marx, y F. Engels. Obras Escogidas en 3 tomos, Tomo II (pp. 175-181). Moscú: Progreso.

Engels, F. (1998). Del socialismo utópico al socialismo científico. Barcelona: Debarris.

Kautsky, K. (1897). Communism in Central Europe in the Time of the Reformation. London: T. Fisher Unwin.

Mannheim, K. (1971). Utopía. En A. Neusüss (Comp.). Utopía (pp. 83-87). Barcelona: Barral Editores.

Marx, K. (1980). Tesis sobre Feuerbach. En K. Marx, y F. Engels. Obras Escogidas en 3 tomos, Tomo I (pp. 7-10). Moscú: Progreso.

Marx, K., y Engels, F. (1980). Obras escogidas en 3 tomos. Moscú: Progreso.

Marx, K., y Engels, F. (2017). El manifiesto comunista. Barcelona: Península.

Sánchez Vázquez, A. (1980). Filosofía de la praxis. México: Grijalbo.

Sánchez Vázquez, A. (1995). Exilio, política y filosofía. Entrevista concedida a Teresa Rodríguez de Lecea. En A.A.V.V. Adolfo Sánchez Vázquez: los trabajos y los días (semblanzas y entrevistas) (pp. 271-293). México: FFyL-UNAM.

Sánchez Vázquez, A. (2000). Del socialismo científico al socialismo utópico. En A. Sánchez Vázquez. El valor del socialismo (pp. 21-64). México: Itaca.

Sánchez Vázquez, A. (2006). Una trayectoria intelectual comprometida. México: FFyLUNAM.

Sánchez Vázquez, A. (2007). En la utopía socialista ¿de qué socialismo hablamos? En: A. Sánchez Vázquez. Entre la realidad y la utopía. Ensayos sobre política, moral y socialismo (pp. 273-290). México: Fondo de Cultura Económica.

Sánchez Vázquez, A. (2015a). La utopía de don Quijote. En: A. Sánchez Vázquez. A tiempo y destiempo. Antología de ensayos (pp. 531-544). México: Fondo de Cultura Económica.

Sánchez Vázquez, A. (2015b). La utopía del "fin de la utopía”. En: A. Sánchez Vázquez. A tiempo y destiempo. Antología de ensayos (pp. 545-566). México: Fondo de Cultura Económica. 